\title{
Correlating Capsaicinoid Levels and Physicochemical Properties of Kimchi and Its Perceived Spiciness
}

\author{
So-Ra Yoon ${ }^{1,+}$, Yun-Mi Dang ${ }^{1, \dagger}{ }^{+}$, Su-Yeon Kim ${ }^{1}$, Su-Yeon You ${ }^{1}$, Mina K. Kim ${ }^{2, *}$ (D) and Ji-Hyoung Ha ${ }^{1, *}$ \\ 1 Hygienic Safety and Analysis Center, World Institute of Kimchi, Gwangju 61755, Korea; \\ sorayoon@wikim.re.kr (S.-R.Y.); ymdang@wikim.re.kr (Y.-M.D.); kss1112@wikim.re.kr (S.-Y.K.); \\ ysy@wikim.re.kr (S.-Y.Y.) \\ 2 Department of Food Science and Human Nutrition, Jeonbuk National University, Jeollabuk-do 54896, Korea \\ * Correspondence: minakim@jbnu.ac.kr (M.K.K.); hajee@wikim.re.kr (J.-H.H.); Tel.: +82-63-270-3879 (M.K.K); \\ +82-62-610-1845 (J.-H.H.) \\ + These authors contributed equally to this work.
}

Citation: Yoon, S.-R.; Dang, Y.-M.; Kim, S.-Y.; You, S.-Y.; Kim, M.K.; Ha, J.-H. Correlating Capsaicinoid Levels and Physicochemical Properties of Kimchi and Its Perceived Spiciness. Foods 2021, 10, 86. https://doi.org/10.3390/ foods10010086

Received: 10 November 2020 Accepted: 31 December 2020 Published: 4 January 2021

Publisher's Note: MDPI stays neutral with regard to jurisdictional clai$\mathrm{ms}$ in published maps and institutional affiliations.

Copyright: (C) 2021 by the authors. Licensee MDPI, Basel, Switzerland. This article is an open access article distributed under the terms and conditions of the Creative Commons Attribution (CC BY) license (https:// creativecommons.org/licenses/by/ $4.0 /)$.

\begin{abstract}
Capsaicinoid content, among other factors, affects the perception of spiciness of commercial kimchi. Here, we investigated whether the physicochemical properties of kimchi affect the spicy taste of capsaicinoids perceived by the tasting. High-performance liquid chromatography (HPLC) was used to evaluate the capsaicinoid content $(\mathrm{mg} / \mathrm{kg})$ of thirteen types of commercial kimchi. The physicochemical properties such as $\mathrm{pH}$, titratable acidity, salinity, free sugar content, and free amino acid content were evaluated, and the spicy strength grade was determined by selected panel to analyze the correlation between these properties. Panels were trained for $48 \mathrm{~h}$ prior to actual evaluation by panel leaders trained for over $1000 \mathrm{~h}$ according to the Spectrum ${ }^{\mathrm{TM}}$ method. Partial correlation analysis was performed to examine other candidate parameters that interfere with the sensory evaluation of spiciness and capsaicinoid content. To express the specific variance after eliminating the effects of other variables, partial correlations were used to estimate the relationships between two variables. We observed a strong correlation between spiciness intensity ratings and capsaicinoid content, with a Pearson's correlation coefficient of 0.78 at $p \leq 0.001$. However, other specific variables may have influenced the relationship between spiciness intensity and total capsaicinoid content. Partial correlation analysis indicated that the free sugar content most strongly affected the relationship between spiciness intensity and capsaicinoid content, showing the largest first-order partial correlation coefficient $\left(\mathrm{r}_{\mathrm{xy} / \mathrm{z}}: 0.091, p \leq 0.01\right)$.
\end{abstract}

Keywords: capsaicinoid; kimchi; partial correlation; Pearson's correlation; spiciness

\section{Introduction}

Kimchi is traditional Korean food made by fermenting leafy vegetables. Kimchi has been listed in the Codex Alimentarius, 2001 (CODEX STAN 223-2001) and was listed in 2006 as one of the five healthiest foods worldwide [1]. Among the various fermented vegetables available in Asian countries such as Zacái, Yancái, and Suncái in China and Tsukemono in Japan [2], Korean-style kimchi contains red pepper (Capsicum annuum) powder and various seasonings, which impart its distinctive pungent-spicy characteristics [3]. Because of its distinctive pungent-spicy perception, red pepper powder is one of the most accepted spices worldwide [4]. Although spiciness is not scientifically considered as a gustative stimulus, unlike sweet, salty, sour, bitter, and umami tastes from cultural perspectives, Asian countries consider the pungent-spicy stimulus produced by red pepper powder as one of the six main taste modalities [5]. The pungent-spicy characteristics of Korean-style kimchi drive consumer preferences among Chinese [6] and American consumers [7,8]. Park et al. [8] reported an increase in the perception of spiciness in kimchi containing increased levels of red pepper powder in the formulation, indicating that red pepper powder is a key contributor to the spicy taste in kimchi. 
As the spicy taste attributed to red pepper powder in kimchi has been identified as one of the key factors influencing consumer preference, a study to determine the spiciness of kimchi was previously conducted [8]. To date, determining spiciness in a food matrix, including kimchi and red pepper powder, depends on the instrumental analysis of capsaicinoids. The levels of capsaicin (CAP) and dihydrocapsaicin (DHCA), which are major components of red pepper powder, can be assessed quantitatively and qualitatively through various assays and analytical instruments. Initially, pepper spiciness was measured using the Scoville organoleptic heat test [9]. In addition to determining the Scoville unit (SU), spectrophotometry [10], colorimetry [11], high-performance liquid chromatography (HPLC) [12], gas chromatography [13], liquid chromatography [14], liquid chromatography mass spectrometry [15], and capillary electrophoresis [16] have been used to analyze the contents of CAP and DHCA. HPLC is a widely used method for precisely quantifying CAP and DHCA [12]. Based on literature reviews, instrumental analysis of CAP and DHCA in food matrices revealed possible interactions between CAP and other quality characteristics such as soluble sugars, organic acids, and amino acids in red peppers [17] and between organic compounds and capsaicinoid content in red pepper [18]. When considering kimchi fermentation, accumulation of organic acids such as lactic acids [7] decreases the $\mathrm{pH}$ of kimchi to 4.2 , potentially influencing its pungent-spicy taste.

Although the abovementioned methods provide the concentrations of CAP and DHCA in food matrices, information on the perceived spiciness from human sensory perspectives is lacking. To date, few studies have examined the pungent-spicy taste in kimchi using human assessors. Chambers et al. [19] reported a sensory lexicon describing commercially available cabbage (Baechu) kimchi. They used $0.4 \mathrm{mg} / \mathrm{kg}$ capsaicin solution as a reference for "heartburn" and Reese's horseradish sauce as a reference for the "pungent" sensation in kimchi. Similarly, Ku et al. [9] investigated the physicochemical and sensory characteristics of radish-based kimchi (Kakdugi) made by red pepper and red pimiento and reported a high correlation between CAP and DHCA and a "hot taste" in kimchi. Instead of solely investigating the spiciness characteristics in kimchi as perceived by human assessors, they used "heat burn", "pungent", and/or "hot taste" as part of the sensory lexicon describing the sensory characteristics of kimchi. Therefore, perceived spiciness from a human sensory perspective remains unclear. Park et al. [8] reported the consumer acceptance of kimchi containing varying levels of red pepper and fish sauce. They found that the ratings of perceived spiciness increased with the levels of red pepper powder and overall consumer acceptability increased with the spiciness of kimchi. However, they used the percentage of red pepper in kimchi as an indicator of spiciness; therefore, the perceived spiciness by a human was not objectively profiled.

Although many factors influence the human perception of spiciness in kimchi, a sensory analysis protocol has not been developed for evaluating the spiciness of kimchi using a trained panel. In this study, we examined whether sensory spiciness caused by capsaicinoids is influenced by the specific physicochemical properties of kimchi such as $\mathrm{pH}$, titratable acidity, salinity, free sugars, and free amino acids. Additionally, we used a partial correlation approach to examine other candidate variables that interfere with two closely related variables; this approach was used to determine the causes of variation in human sensory perception of the intensity of pungent stimuli. Partial correlations were used to estimate the correlation between two variables and define the specific variance explained by eliminating the effect of other variables.

\section{Materials and Methods}

\subsection{Kimchi Samples}

Thirteen types of kimchi, produced by various manufacturers and with known variations in spiciness and CAP concentrations, were purchased from grocery stores in Gwangju, Korea. All ingredients in the kimchi samples are listed in Table 1 based on the package labeling. Upon purchase, all kimchi samples were blended (Philips HR1372, Amsterdam, The Netherlands) and immediately analyzed. 
Table 1. Ingredients in 13 commercial kimchi samples in this study.

\begin{tabular}{|c|c|}
\hline Sample Number & Ingredients Listed on Food Labels on the Packages \\
\hline 1 & $\begin{array}{l}\text { Salted kimchi cabbage, radish, white rice paste, red pepper powder, salted anchovy sauce, spring onion, garlic, } \\
\text { salted shrimp, ginger, sucrose, mushroom }\end{array}$ \\
\hline 2 & $\begin{array}{l}\text { Salted kimchi cabbage, radish, glutinous rice paste, garlic, red pepper powder, kelp extract, salted anchovy } \\
\text { sauce, vegetables, salted shrimp sauce, spring onion, fermented vegetable lactic acid bacteria broth, onion, } \\
\text { lactic acid bacteria broth, gelatinization rice powder, ginger }\end{array}$ \\
\hline 3 & $\begin{array}{l}\text { Salted kimchi cabbage, red pepper powder, garlic, radish, spring onion, onion, ginger, salt, sucrose, salted } \\
\text { anchovy sauce, salted shrimp }\end{array}$ \\
\hline 4 & $\begin{array}{l}\text { Salted kimchi cabbage, radish, red pepper powder, fish sauce, kimchi seasoning paste, garlic, pear puree, } \\
\text { spring onion, vegetables, salted shrimp sauce, spring onion, salted anchovy sauce, ginger, fermented lactic } \\
\text { acid bacteria broth, crystalline fructose }\end{array}$ \\
\hline 5 & $\begin{array}{l}\text { Salted kimchi cabbage, radish, purified water, red pepper powder, rice powder, salted anchovy sauce, garlic, } \\
\text { onion, spring onion, chives / leaf mustard, salted shrimp, water parsley, sucrose, pear, refined salt, chestnut, } \\
\text { ginger, wheat extract, xanthan gum }\end{array}$ \\
\hline 6 & $\begin{array}{l}\text { Salted kimchi cabbage, radish, dried red pepper, garlic, onion, spring onion, salted anchovy sauce, salted } \\
\text { shrimp, sucrose, ginger, red pepper powder, chives/leaf mustard, glutinous rice paste, refined salt, mushroom }\end{array}$ \\
\hline 7 & $\begin{array}{l}\text { Salted kimchi cabbage, radish, glutinous rice paste, red pepper powder, garlic, onion, salted anchovy sauce, } \\
\text { salted shrimp, salted anchovy, spring onion, dried red pepper, chives/leaf mustard, kelp stock, ginger, sea } \\
\text { staghorn }\end{array}$ \\
\hline 8 & $\begin{array}{l}\text { Salted kimchi cabbage, sliced radish, red pepper powder, garlic, spring onion, salted anchovy sauce, salted } \\
\text { shrimp, onion, ginger, red pepper, sucrose, purified water, flour paste, refined salt, monosodium L-glutamate } \\
\text { (flavor enhancer) }\end{array}$ \\
\hline 9 & $\begin{array}{l}\text { Salted cabbage kimchi, red pepper powder, anchovy sauce, radish, glutinous rice paste, salted shrimp, onion, } \\
\text { garlic, onion, ginger, solar salt }\end{array}$ \\
\hline 10 & $\begin{array}{l}\text { Salted cabbage kimchi, radish, red pepper powder, garlic, salted anchovy sauce, salted sand lance sauce, } \\
\text { spring onion, water parsley, onion, pear, paprika, salted shrimp, sucrose, glutinous rice paste, ginger, } \\
\text { monosodium L-glutamate (flavor enhancer) }\end{array}$ \\
\hline 11 & $\begin{array}{l}\text { Kimchi cabbage, radish, red pepper powder, garlic, ginger, spring onion, leaf mustard/chives, onion, apple, } \\
\text { salted shrimp, fermented anchovy sauce with meju (fermented soybean lump) powder, natural seasoning, } \\
\text { glutinous rice paste, starch syrup, glucose, enzymatically modified stevia glucosyl stevia, kimchi lactic acid } \\
\text { bacteria powder (Leuconostoc mesenteroides) }\end{array}$ \\
\hline 12 & $\begin{array}{l}\text { Kimchi cabbage, radish, red pepper powder, salted anchovy sauce, garlic, onion, salted shrimp, refined salt, } \\
\text { chives, ginger, sucrose }\end{array}$ \\
\hline 13 & $\begin{array}{l}\text { Salted cabbage kimchi, radish, red pepper powder, garlic, salted shrimp, salted anchovy, ginger, onion, } \\
\text { glutinous rice paste, sucrose }\end{array}$ \\
\hline
\end{tabular}

\subsection{Determination of Physicochemical Properties of Kimchi}

\subsubsection{Assessment of Capsaicin and Dihydrocapsaicin Content}

The CAP and DHCA contents were analyzed as previously described [20] with minor modifications. Briefly, $15 \mathrm{~mL}$ methanol was added to a vial containing $2.5 \mathrm{~g}$ of homogenized kimchi and two or three glass beads. The mixture was placed on a heating block at $90^{\circ} \mathrm{C}$ for $1 \mathrm{~h}$ and then cooled. The cooled extract was passed through a filter paper $(8 \mu \mathrm{m}$, Whatman No. 2, Kent, UK), and methanol was added to the filtered solution to bring the volume to $25 \mathrm{~mL}$; the solution was filtered again through a $0.2-\mu \mathrm{m}$ syringe filter (Millipore, Billerica, MA, USA). The analysis was conducted using HPLC Model 1260 Infinity; Agilent Technologies, Santa Clara, CA, USA) coupled with a fluorescence detector (Agilent Technologies, Santa Clara, CA, USA). Excitation and emission wavelengths were set to 208 and $325 \mathrm{~nm}$, respectively. To separate CAP and DHCA, a Lachrom Ultra C18 column $(2 \times 50 \mathrm{~mm}, 2 \mu \mathrm{L}$; Hitachi, Tokyo, Japan) was used with $0.1 \%$ acetic acid and acetonitrile $(6: 4, v / v)$ as mobile phase at a flow rate of $0.6 \mathrm{~mL} / \mathrm{min}$ with an injection volume of $2 \mu \mathrm{L}$.

\subsection{2. $\mathrm{pH}$ and Titratable Acidity}

The homogenized kimchi samples were filtered to obtain the filtrate used to measure the $\mathrm{pH}$ and titratable acidity. $\mathrm{pH}$ was measured using a $\mathrm{pH}$ meter (Model Titro Line 5000; SI Analytics, Mainz, Germany). The kimchi was titrated to $\mathrm{pH} 8.3$ by adding $0.1 \mathrm{~N}$ sodium 
hydroxide (NaOH; Daejung Chemical, Shiheung, Korea) solution, and titratable acidity was calculated as the percentage of lactic acid using Equation (1).

$$
\text { Titratable acidity }(\%)=\frac{(A \times F \times D) \times 0.009}{S} \times 100
$$

where $A$ is the titration volume $(\mathrm{mL})$ of $0.1 \mathrm{~N} \mathrm{NaOH} ; F$ is the titer of $0.1 \mathrm{~N} \mathrm{NaOH} ; D$ is the dilution factor of the sample; 0.009 is lactic acid corresponding to $1 \mathrm{~mL} 0.1 \mathrm{~N} \mathrm{NaOH}$; and $S$ is sample weight (g).

\subsubsection{Salinity}

Salinity was measured using the Mohr method [21]. Sodium chloride, which reacts with silver nitrate, is precipitated to silver chloride and acquires a reddish-brown color by reacting with potassium chromate. To measure kimchi salinity, $2.5 \mathrm{~g}$ homogenized kimchi were combined with $47.5 \mathrm{~mL}$ distilled water and passed through filter paper $(8 \mathrm{~mm}$, Whatman No. 2). Next, $200 \mu \mathrm{L}$ of $10 \%$ potassium chromate were added to $10 \mathrm{~mL}$ filtrate and titrated with $0.02 \mathrm{~N}$ silver nitrate until the color of the mixture changed from clear yellow to reddish-brown. Salinity was calculated using Equation (2).

$$
\text { Salinity }(\%)=\frac{(A \times F \times D) \times 0.00117}{S} \times 100
$$

where $A$ is the titration volume of $0.02 \mathrm{~N}$ silver nitrate $(\mathrm{mL}) ; F$ is the titer of $0.02 \mathrm{~N}$ silver nitrate; $D$ is the dilution factor; 0.00117 is the sodium chloride corresponding to $1 \mathrm{~mL}$ $0.02 \mathrm{~N}$ silver nitrate; and $S$ is the sample weight $(\mathrm{g})$.

\subsubsection{Determination of Free Sugar Content}

After filtering the homogenized kimchi samples through sterilized gauze, the obtained kimchi juice (filtrate) was extracted in a water bath at $85^{\circ} \mathrm{C}$ for $25 \mathrm{~min}$, cooled to room temperature $\left(18 \pm 2{ }^{\circ} \mathrm{C}\right)$, and passed through a $0.2-\mu \mathrm{m}$ syringe filter. Analysis was performed using HPLC equipped with a refractive index detector. To separate the sugars (glucose, fructose, sucrose, maltose, mannitol, and sorbitol), we used an Asahipak NH2P-504 E column $(250 \times 4.6 \mathrm{~mm}$; Shodex, Tokyo, Japan) with acetonitrile $(75 \%, v / v)$ as the mobile phase at a flow rate of $1 \mathrm{~mL} / \mathrm{min}$ using a described protocol [22].

\subsubsection{Determination of Free Amino Acid Content}

To extract free amino acids, each homogenized kimchi sample $(1 \mathrm{~g})$ was mixed with $5 \mathrm{~mL}$ of $5 \%$ trichloroacetic acid and centrifuged at $8000 \times g$ for $20 \mathrm{~min}$. Next, $1 \mathrm{~mL}$ supernatant was combined with $0.02 \mathrm{~N}$ hydrochloric acid and passed through a $0.2-\mu \mathrm{m}$ syringe filter. An automatic amino acid analyzer (Model L-8900; Hitachi, Tokyo, Japan), equipped with an ion-exchange column $(4.6 \times 60 \mathrm{~nm}$ HPLC pack column and \#2622 SCF PF column; Hitachi, Tokyo, Japan), and L-8900 buffer solution (Wako Pure Chemical Industries, Osaka, Japan) were used to analyze the free amino acid content. The flow rate was $0.35 \mathrm{~mL} / \mathrm{min}$, and absorbance was set to 440 and $570 \mathrm{~nm}$.

\subsection{Descriptive Analysis of the Spiciness of Kimchi}

\subsubsection{Panel Selection}

Descriptive analysis was conducted following the ethical guidelines of the Helsinki Declaration and signed informed consent was obtained from all participants of the descriptive sensory panel before evaluation. Participants in the panel were recruited from the World Institute of Kimchi (Gwangju, Korea) based on their interests and experience in sensory evaluation. The enrolled participants were assessed for their ability to discriminate the five tastes (sweet, salt, sour, bitter, and umami), aroma recognition, and spiciness tolerance. Those who passed the screening test participated in the panel training. The selected panel comprised six participants, including a panel leader, aged from 27 to 39 years (1 male and 5 females). 


\subsubsection{Reference Sample Evaluation}

To establish a frame of reference for the range of sample concentrations, capsaicin solutions of various concentrations were prepared according to the method of Lee and Kim [20]. Briefly, $0.02 \mathrm{~g}$ of $95 \%$ capsaicin (Sigma-Aldrich, St Louis, MO, USA) was mixed with $0.7 \mathrm{~g}$ food-grade polysorbate- 80 (Sigma-Aldrich, St Louis, MO, USA) and dissolved by heating on a hot plate $\left(40 \pm 2{ }^{\circ} \mathrm{C}\right)$. After cooling, the mixture was adjusted to a volume of $100 \mathrm{~mL}$ by adding water at a temperature of $70^{\circ} \mathrm{C}$. The prepared capsaicin stock solution $(200 \mathrm{mg} / \mathrm{kg}$ ) was diluted to various concentrations (from 0.5 to $30.0 \mathrm{ppm}, w / v$ ), and served as the sensory reference for pungent-spicy taste in kimchi.

\subsubsection{Panel Training}

The panel was trained for $48 \mathrm{~h}$ before the actual evaluation. The panel leader had more than $1000 \mathrm{~h}$ of training in the evaluation of various food products using the Universal scale in the Spectrum ${ }^{\mathrm{TM}}$ method. Panel training was performed following the ASTM method of descriptive analysis testing for sensory evaluation (ASTM: MNL13) [23]. To maximize the evaluation ability, panelists were instructed to avoid food with strong aroma and flavor, coffee, and alcoholic beverages for $2 \mathrm{~h}$ before the evaluation. All participants were familiar with commercial kimchi and with the spiciness taste in kimchi. Before evaluation, panelists were familiarized with the different types of commercial kimchi. During training, panelists were taught the Universal scale in the Spectrum ${ }^{\mathrm{TM}}$ method using basic taste solutions such as sucrose for sweet, salt for salty, citric acid for sour, caffeine for bitter, and monosodium glutamate for umami tastes [24]. Next, they were trained to understand the rating system for spiciness using capsaicin solution $(2=0.5 \mathrm{mg} / \mathrm{kg}$ capsaicin solution; $4=2.0 \mathrm{mg} / \mathrm{kg}$ capsaicin solution; $7=4.0 \mathrm{mg} / \mathrm{kg}$ capsaicin solution; $9=6.0 \mathrm{mg} / \mathrm{kg}$ capsaicin solution). During training, the sample evaluation protocol for the spiciness taste of kimchi and palate cleanser for removing residual spiciness in the mouth were evaluated. To evaluate spiciness using capsaicin solution, $10 \mathrm{~mL}$ of capsaicin solution was consumed and rinsed around the palate for $10 \mathrm{~s}$ before expectoration; the intensity of spiciness was rated within $10 \mathrm{~s}$. Participants were then asked to use whipping cream with $5 \%$ sucrose $\left(22 \pm 2{ }^{\circ} \mathrm{C}, w / v\right)$ unsalted crackers $(5 \mathrm{~g})$, and water $\left(22 \pm 2{ }^{\circ} \mathrm{C}, w / v\right)$ as a primary palate cleanser. In addition to the cleansing protocol, a 10-min resting gap period between tasting of each sample was enforced.

\subsubsection{Kimchi Sample Evaluation}

All samples (10 g each) were served in a white plastic cup (diameter: $70 \mathrm{~mm}$, length: $35 \mathrm{~mm}$ ) marked with a three-digit number generated in random order for each evaluation. Kimchi was served to the panel in a blended form to minimize part-by-part variations (i.e., leafy part and stem part of kimchi) in spiciness. Evaluations were conducted in a sensory booth at room temperature $\left(18 \pm 2{ }^{\circ} \mathrm{C}\right)$. Before evaluating the spiciness of kimchi, the panelists calibrated their palate using capsaicin reference [0.5, 2.0, 4.0, 6.0 ppm $(w / v)]$ in ascending order. The trained panelists rated the spiciness of each kimchi sample individually, and the orders of presentation of kimchi samples among panelists followed a randomized and balanced design.

\subsection{Analysis Using Simple and Partial Correlation Coefficients}

If the correlation is explicitly defined between $X$ and $Y$ without conditioning on any variable, the order of the partial correlation coefficient is zero. This can generally be defined as Pearson's correlation (Equation (3)). The order is $\mathrm{x}$ when the correlation is calculated after conditioning on $x$ number of different variables other than A and B [25]. Equation (4) generally defines the first three orders of partial correlations.

Zero-order correlation:

$$
r_{X Y}=\frac{\operatorname{cov}(X, Y)}{\sqrt{\operatorname{var}(X) \times \operatorname{var}(Y)}}
$$


First-order partial correlation:

$$
r_{X Y / Z}=\frac{\left[r_{X Y}-\left(r_{Y Z} \times r_{X Z}\right)\right]}{\sqrt{\left(1-r_{Y Z}^{2}\right)\left(1-r_{X Z}^{2}\right)}}
$$

where $r_{x y / z}$ is the correlation coefficient suspected of being affected by specific variables (Z: each physicochemical property such as $\mathrm{pH}$, titratable acidity, salinity, free sugars, and free amino acids); $r_{y z}$ is the correlation of corresponding specific variables with the rating of spiciness; and $r_{x z}$ is the correlation of the capsaicinoid content variable with specific variables $(Z)$.

\subsection{Statistical Analysis}

All results are presented as the mean \pm standard deviation. Data were analyzed using SPSS v.19 for Windows (SPSS, Inc., Chicago, IL, USA). Analysis of variance was used to verify the significance of differences among the physicochemical properties of kimchi samples regarding the spiciness intensity of each sample. Correlations were analyzed using R program (http: / / www.r-project.org). $p<0.05$ was considered as statistically significant.

\section{Results and Discussion}

\subsection{Physicochemical Properties of Commercial Kimchi}

The ingredients and fermentation period of each kimchi sample varied; therefore, the sensory attributes of these samples differed, necessitating assessment of the correlation between spiciness and physicochemical components. Detection and quantitative assessment of the capsaicin content were used to profile the spiciness-related characteristics of commercial kimchi. Except for salinity, most physicochemical properties of kimchi such as $\mathrm{pH}$, titratable acidity, free sugars, and free amino acids change under conditions of lactic acid fermentation [26]. Therefore, as the commercial kimchi products were purchased immediately after manufacture, maturity among kimchi samples did not influence the results.

Physicochemical properties such as $\mathrm{pH}$, titratable acidity, salinity, free sugar content, and free amino acid content of kimchi samples are shown in Table 2. The $\mathrm{pH}$ values of all kimchi samples widely varied from 4.13 to 6.32 . Commercial kimchi generally has various $\mathrm{pH}$ values between 4.0 and 6.0 when freshly prepared following the manufacturers' individual recipes; this value gradually decreases because of organic acids generated by lactic acid bacteria during fermentation $[27,28]$. The titratable acidities (TAs) of all kimchi samples ranged from 0.27 to 0.84 for unfermented samples of packaged kimchi. Previous studies reported that commercial kimchi has optimum flavor and texture attributes at a $\mathrm{pH}$ of 4.5 and/or TA of $0.6-0.9 \%$ [29,30]. Several samples in this study met the criteria for optimum flavor and texture attributes (Samples 4, 5, 10, and 12); however, our study did not focus on the flavor and texture of kimchi but rather on its spiciness. Overall, the $\mathrm{pH}$ and TAs of our kimchi samples were within the range of those of reported commercial kimchi samples $[27,29]$. The salinity of kimchi samples was between $1.34 \%$ and $2.09 \%$. According to Jung et al. [31], free sugar content plays a major role in the flavor development of kimchi, as it alters the composition of lactic acid bacterial communities, which generates a sweet taste. Table 2 shows that the free sugar content in our kimchi samples ranged from 19.92 to $52.24 \mathrm{mg} / \mathrm{mL}$. Among free sugars, fructose and glucose accounted for most of the sugar content in our kimchi samples at $44.07 \%$ and $41.37 \%$, respectively, regarding the total free sugar content (Table S1). The content of mannitol, sucrose, maltose, and sorbitol in our commercial kimchi samples was below 15\%. Free amino acids in kimchi, which are also known to contribute to kimchi flavor, were analyzed. Among the 40 free amino acids, 32 varied in their concentration among the commercial kimchi products examined in this study. Glutamine, glutamic acid, alanine, and $\gamma$-aminobutyric acid were generally predominant in our kimchi samples, accounting for approximately $47 \%$ of the total free 
amino acid content (Table S2). The generation of glutamic acid in kimchi is caused either by glutaminase activity or by proteolysis of glutamine by lactic acid bacteria [32].

Table 2. Physicochemical properties of the 13 commercial kimchi samples.

\begin{tabular}{|c|c|c|c|c|c|}
\hline Sample Number & $\mathrm{pH}$ & Total Acidity (\%) & Salinity (\%) & Free Sugars (mg/mL) & Free Amino Acids (mg/kg) \\
\hline 1 & $5.7 \pm 0.0^{\mathrm{e}}$ & $0.3 \pm 0.0^{\mathrm{c}}$ & $1.6 \pm 0.0^{f}$ & $42.5 \pm 0.8^{\mathrm{f}}$ & $3562.7 \pm 63.5^{b}$ \\
\hline 2 & $6.1 \pm 0.0^{j}$ & $0.2 \pm 0.0^{\mathrm{a}}$ & $1.5 \pm 0.0^{\mathrm{d}}$ & $41.7 \pm 1.2^{\mathrm{f}}$ & $4035.7 \pm 148.1^{\mathrm{c}}$ \\
\hline 3 & $5.7 \pm 0.0^{f}$ & $0.4 \pm 0.0^{\mathrm{e}}$ & $1.8 \pm 0.0^{\mathrm{i}}$ & $43.8 \pm 3.5^{f}$ & $5122.4 \pm 220.0 \mathrm{~g}$ \\
\hline 4 & $4.3 \pm 0.0^{b}$ & $0.8 \pm 0.0^{\mathrm{i}}$ & $1.3 \pm 0.0^{\mathrm{a}}$ & $25.8 \pm 0.2^{b c}$ & $4345.5 \pm 245.3^{\mathrm{d}}$ \\
\hline 5 & $4.6 \pm 0.0^{\mathrm{c}}$ & $0.5 \pm 0.0^{g}$ & $1.5 \pm 0.0^{\mathrm{de}}$ & $27.3 \pm 0.6^{c}$ & $3724.1 \pm 66.5^{b}$ \\
\hline 6 & $6.3 \pm 0.0^{\mathrm{k}}$ & $0.3 \pm 0.0^{b}$ & $1.4 \pm 0.0^{\mathrm{c}}$ & $33.1 \pm 1.1^{d}$ & $4205.7 \pm 108.4^{\mathrm{cd}}$ \\
\hline 7 & $6.0 \pm 0.0^{\mathrm{i}}$ & $0.3 \pm 0.0^{\mathrm{d}}$ & $1.5 \pm 0.0^{\mathrm{e}}$ & $36.1 \pm 1.0^{\mathrm{e}}$ & $4363.6 \pm 109.2 \mathrm{de}$ \\
\hline 8 & $5.1 \pm 0.0^{\mathrm{d}}$ & $0.4 \pm 0.0^{f}$ & $1.4 \pm 0.0^{b}$ & $32.1 \pm 0.6^{\mathrm{d}}$ & $4840.5 \pm 161.7^{\mathrm{f}}$ \\
\hline 9 & $5.8 \pm 0.0 \mathrm{~g}$ & $0.4 \pm 0.0^{\mathrm{e}}$ & $1.7 \pm 0.0^{\mathrm{h}}$ & $31.3 \pm 0.6^{\mathrm{d}}$ & $4637.3 \pm 150.6^{\text {ef }}$ \\
\hline 10 & $4.1 \pm 0.0^{\mathrm{a}}$ & $0.7 \pm 0.0^{\mathrm{h}}$ & $1.8 \pm 0.0^{\mathrm{h}}$ & $19.9 \pm 0.7^{\mathrm{a}}$ & $2855.6 \pm 100.4^{\mathrm{a}}$ \\
\hline 11 & $5.9 \pm 0.0^{\mathrm{h}}$ & $0.3 \pm 0.0^{b}$ & $1.5 \pm 0.0^{\mathrm{de}}$ & $37.4 \pm 0.1^{\mathrm{e}}$ & $4311.4 \pm 19.9^{\mathrm{cd}}$ \\
\hline 12 & $4.6 \pm 0.0^{\mathrm{c}}$ & $0.7 \pm 0.0^{\mathrm{h}}$ & $2.0 \pm 0.0^{j}$ & $23.8 \pm 0.7^{b}$ & $4701.7 \pm 121.9^{f}$ \\
\hline 13 & $5.8 \pm 0.0^{g}$ & $0.5 \pm 0.0^{g}$ & $1.7 \pm 0.0^{\mathrm{g}}$ & $52.2 \pm 0.5^{\mathrm{g}}$ & $7682.1 \pm 333.0^{h}$ \\
\hline
\end{tabular}

${ }^{\mathrm{a}-\mathrm{h}}$ Different small letters in a column indicate significant differences $(\alpha=0.05)$ between mean values.

\subsection{Capsaicinoid Content of 13 Commercial Kimchi Samples}

Capsaicinoid, which is one compound responsible for pungent taste, provides an irritating stimulus and is the principal chemical component of red pepper powder used to impart the pungent taste to kimchi. CAP and DHCA account for most capsaicinoid content, and a previous study reported that CAP and DHCA contribute equally to the spiciness intensity [33]. Therefore, total capsaicinoid, which included CAP and DHCA, was reported as an instrumental analysis of the spiciness of commercial kimchi samples (Table 3). A representative chromatogram of CAP and DHCA reference standards, along with their retention times, is shown in Figure 1. The retention times of CAP and DHCA were 2.7 and $4.7 \mathrm{~min}$, respectively. The total capsaicinoid content of the 13 kimchi samples used in our study ranged from 9.02 to $30.50 \mathrm{mg} / \mathrm{kg}$ (Table 3). As shown in Table 3, our results indicate that spiciness did not depend exclusively on the mean total capsaicinoid content; additional factors, other than total capsaicinoid content, influenced the spiciness intensity of kimchi (Figure 2).

Table 3. Capsaicinoid content of 13 commercial kimchi samples.

\begin{tabular}{ccc}
\hline Sample Number & $\begin{array}{c}\text { Capsaicinoid Content } \\
(\mathbf{m g} / \mathbf{k g})\end{array}$ & $\begin{array}{c}\text { Spiciness Intensity Rating } \\
\text { (15-Point Universal Scale in Spectrum }^{\text {TM}} \text { ) }\end{array}$ \\
\hline 1 & $9.0 \pm 1.0^{\mathrm{a}}$ & $1.7^{\mathrm{a}}$ \\
2 & $9.6 \pm 1.1^{\mathrm{a}}$ & $2.7^{\mathrm{b}}$ \\
3 & $9.8 \pm 1.1^{\mathrm{a}}$ & $2.2^{\mathrm{ab}}$ \\
4 & $10.3 \pm 1.2^{\mathrm{a}}$ & $1.9^{\mathrm{a}}$ \\
5 & $12.6 \pm 1.1^{\mathrm{b}}$ & $3.9^{\mathrm{c}}$ \\
6 & $12.7 \pm 1.1^{\mathrm{b}}$ & $2.4^{\mathrm{ab}}$ \\
7 & $14.4 \pm 1.1^{\mathrm{b}}$ & $2.0^{\mathrm{ab}}$ \\
8 & $16.9 \pm 1.4^{\mathrm{c}}$ & $3.5^{\mathrm{bc}}$ \\
9 & $17.7 \pm 1.1^{\mathrm{c}}$ & $3.4^{\mathrm{bc}}$ \\
10 & $20.3 \pm 1.0^{\mathrm{d}}$ & $5.2^{\mathrm{d}}$ \\
11 & $20.4 \pm 1.5^{\mathrm{d}}$ & $1.7^{\mathrm{a}}$ \\
12 & $26.7 \pm 1.0^{\mathrm{e}}$ & $6.7^{\mathrm{e}}$ \\
13 & $30.5 \pm 1.0^{\mathrm{f}}$ & $5.5^{\mathrm{de}}$ \\
\hline
\end{tabular}

\footnotetext{
${ }^{1}$ Capsaicinoid content including capsaicin and dihydrocapsaicin. ${ }^{a-f}$ Different small letters in a column indicate significant differences $(p<0.05)$ between mean values.
} 


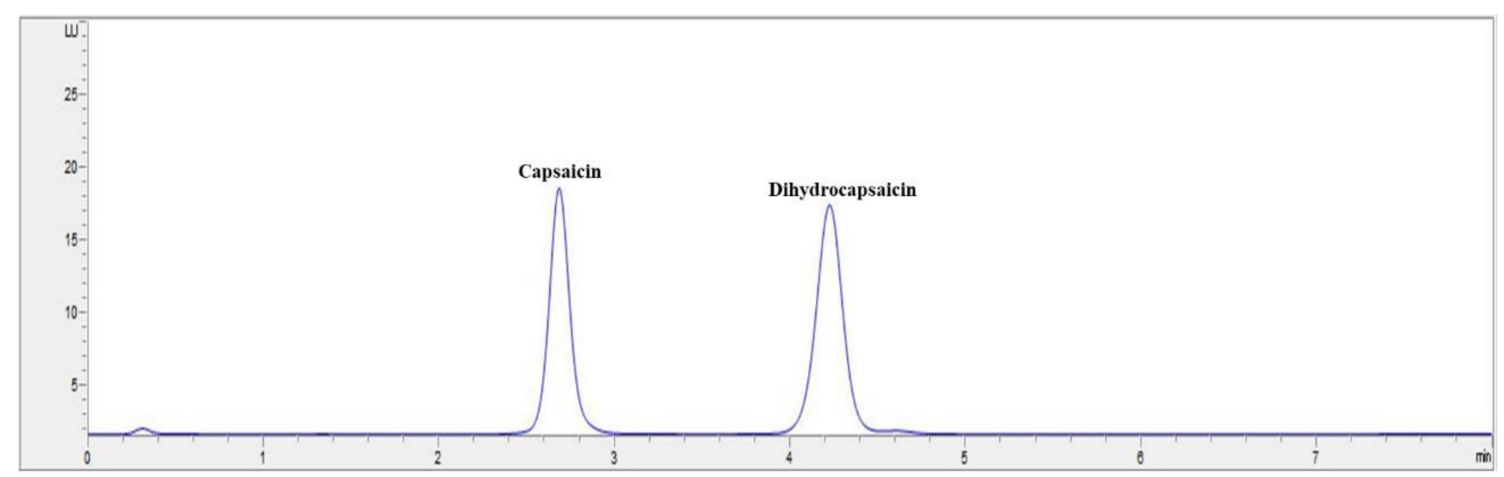

(a)

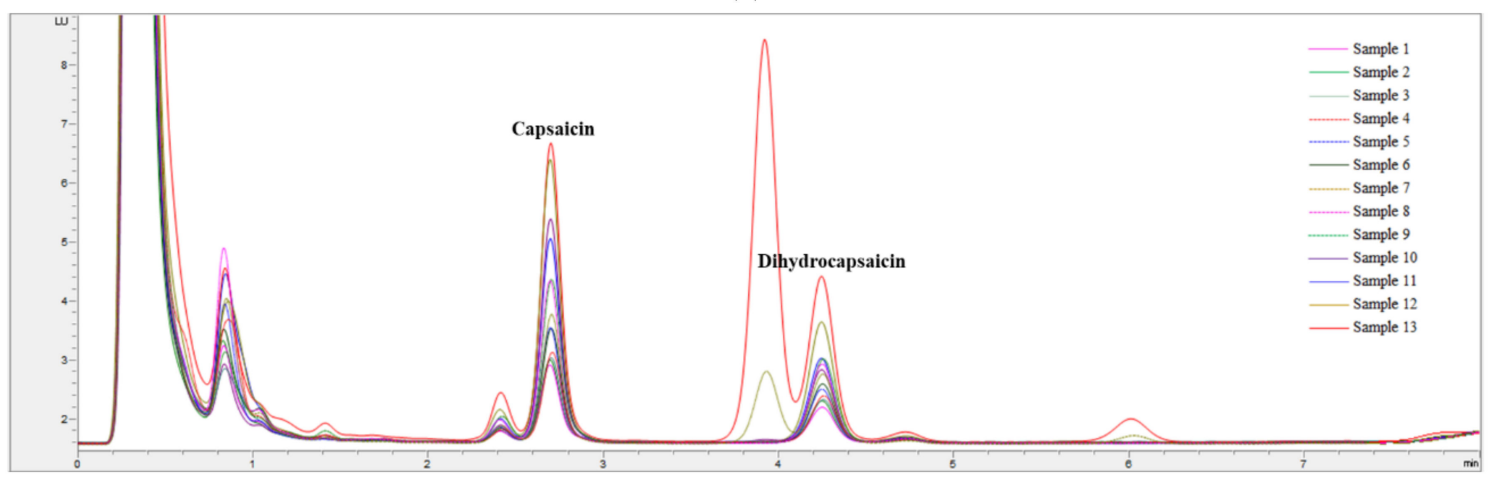

(b)

Figure 1. High-performance liquid chromatography (HPLC) chromatograms of: (a) a standard solution containing capsaicin and dihydrocapsaicin; and (b) capsaicin and dihydrocapsaicin in 13 commercial kimchi samples.

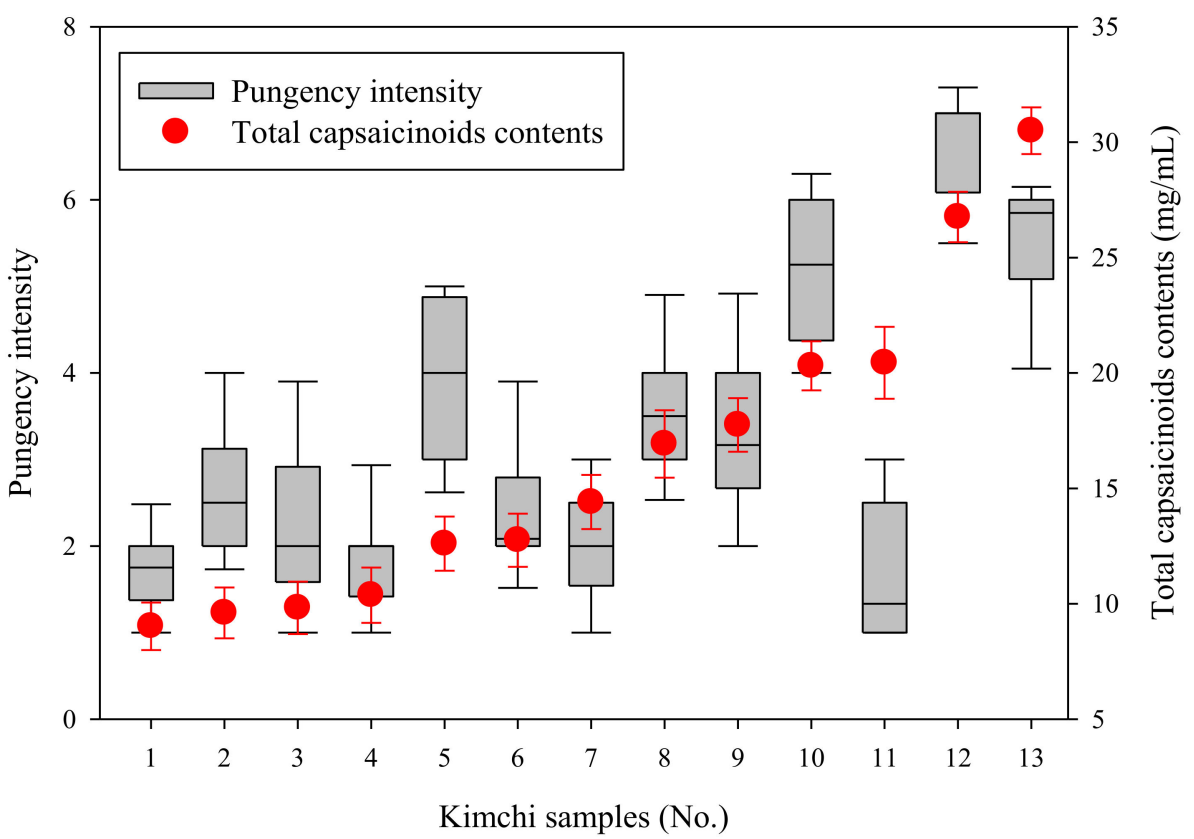

Figure 2. Sensory spiciness evaluation of commercial kimchi samples (left $Y$-axis). Total capsaicinoid content of commercial kimchi samples (right $Y$-axis). The results of sensory evaluation assessing the spiciness and mean capsaicinoid content of our kimchi samples are represented in box plots and scatter plots, respectively. The box plots show the lowest, median, and highest data points, as well as the spread and distribution of spiciness intensity values. 


\subsection{Sensory Evaluation of Spiciness of Commercial Kimchi}

The spiciness intensities of our kimchi samples corresponding to that of capsaicin solutions of $0.5,2.0,4.0$, and $6.0 \mathrm{ppm}(w / v)$ were denoted as scores of " 1 ", " 4 ", " 7 ", and "9", respectively. Among our kimchi samples, the lowest spiciness intensity (1) was similar to that of $0.5 \mathrm{ppm}(w / v)$ capsaicin solution, whereas the maximum (9) spiciness intensity was similar to that of $6.0 \mathrm{ppm}(w / v)$ capsaicin concentration. This maximum level was slightly higher than the spiciest kimchi samples used in our study. None of our kimchi samples exceeded the spiciness intensity of $6.0 \mathrm{ppm}(w / v)$ capsaicin solution. The mean values of spiciness intensity were estimated using the results obtained from individual participants. The change in the values for spiciness intensity and mean total capsaicinoid content indicated a direct relationship between spiciness intensity and mean total capsaicinoid content. According to Schneider et al. [34], the distribution of values in a box plot can be explained by individual differences in the spiciness perception of the panelists, which is then reflected in the assigned spiciness intensity scores. Even kimchi samples with mostly the same mean total capsaicinoid content often differed in sensory spiciness ratings. For example, the total capsaicinoid content of Sample 11 was nearly twice that of Sample 4; however, the sensory spiciness ratings of Samples 4 and 11 did not differ significantly. Furthermore, the total capsaicinoid contents of Samples 10 and 11 were similar, whereas their sensory spiciness ratings differed significantly. These results indicate that factors such as the physicochemical properties of kimchi can influence the perception of spiciness.

\subsection{Correlation between Physicochemical Parameters and Spiciness}

To confirm the results shown in Table 3, Pearson's correlation coefficient (r) (Figure 3) was analyzed. Among the seven factors, four (spiciness intensity rating, total acidity, salinity, and free amino acids) were positively correlated with an increase in capsaicinoid content; one factor $(\mathrm{pH})$ was negatively correlated with the capsaicinoid content; and zero correlations were observed between the free sugar content and capsaicinoid content.

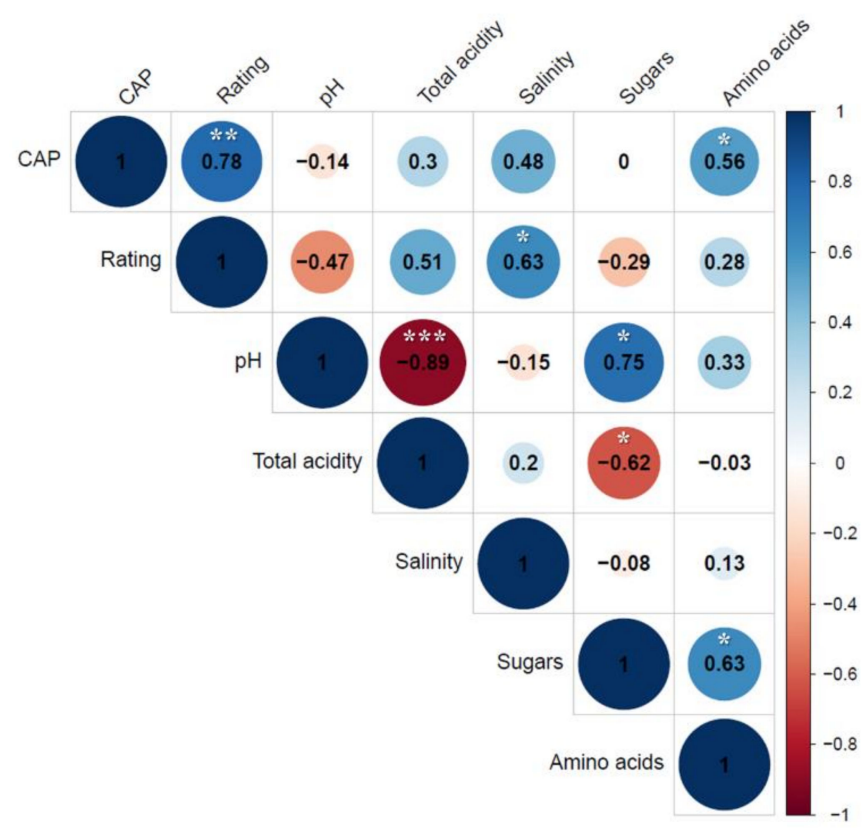

Figure 3. Correlation coefficient matrix of sensory spiciness evaluation and physicochemical parameters in commercial kimchi samples. Positive coefficients are represented by blue circles, which indicate a direct relationship between variables in the matrix, and negative coefficients are shown as red circles, which reflect an inverse relationship. ${ }^{*} p \leq 0.05,{ }^{* *} p \leq 0.01,{ }^{* * *} p \leq 0.001$. 
We observed a strong relationship of 0.78 at $p \leq 0.01$ between spiciness intensity ratings and the capsaicinoid content. Although we investigated the overall correlation coefficients between physicochemical properties and spiciness intensity ratings, our results suggest that physicochemical properties affect the taste of spiciness of kimchi. Pearson's correlation coefficient ( $r$ ) is widely used to determine the linear relationships between continuous random factors [35]. However, this value alone cannot differentiate the effects of direct and indirect associations between various factors. Correlation is a statistical technique used to calculate Pearson's correlation between independent and dependent variables while controlling/eliminating the effects of one or more other correlation variables. Hence, partial correlations are used in many studies pertaining to medicine, metabolomics, genomics, and cognitive psychology.

According to Melissa et al. [36], an association between variables $X$ and $Y$ can occur in various manners, such as a direct relationship $X \rightarrow Y$ co-regulated by a third variable $Z$ (i.e., $Z \rightarrow X$ and $Z \rightarrow Y$ ), or as an indirect relationship $X \rightarrow Z \rightarrow Y$. These relationships are shown in Figure 4, which illustrates how: (a) variable $Z$ is not correlated with both variables $X$ and Y; (b) only the random variable $Y$ is correlated with variable $Z$; and (c) variable $Z$ is correlated with both variables $X$ and $Y$. Figure 4 a shows that variable $Z$ is independent of both variable $X$ and variable $Y$; thus, both Pearson's correlation coefficient and the partial correlation coefficient should theoretically be identical. Because variable $Z$ correlates with variable $X$ and variable $Y$ in Figure $4 b, c$, a partial correlation is established. When variable $X$ alone is correlated with $Z$, as illustrated in Figure $4 b$, Pearson's correlation coefficients of variables $X$ and $Y$ differ depending on the influence of variable $Z$ on variable $X$. Figure $4 c$ shows that the two correlation coefficients are dissimilar.

(a)

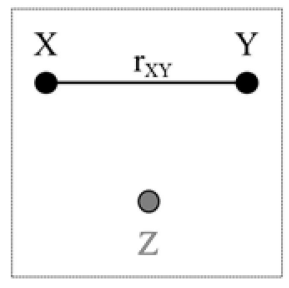

(b)

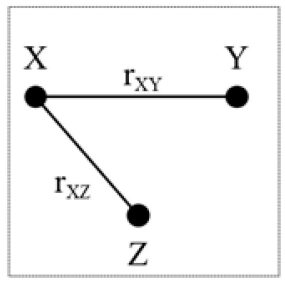

(c)

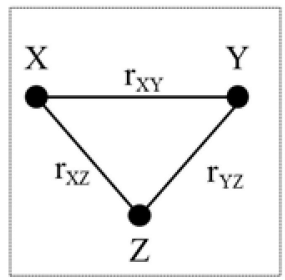

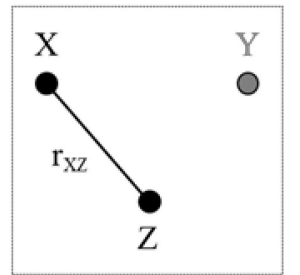
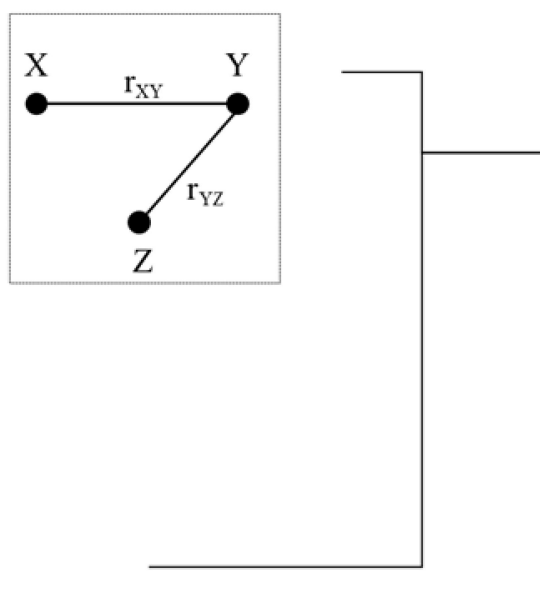

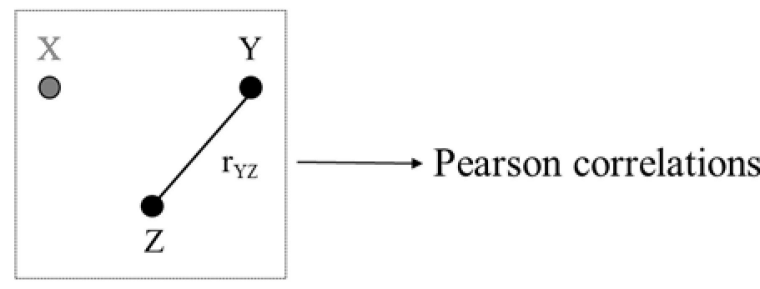

- $\mathrm{X}$ : capsaicin content

- $\mathrm{Y}$ : the rating of spiciness intensity

- $\mathrm{Z}: \mathrm{pH}$, titratable acidity, salinity, free sugars, or free amino acids

Figure 4. Graphical illustration of Pearson's and partial correlations among the three random variables X, Y, and Z: (a) Pearson correlations; (b) and (c) partial correlations.

In this study, we used a partial correlation approach to investigate parameters that interfere with two closely related parameters and determine the causes for variation in the human sensory perception of spiciness intensity. The partial correlation coefficient of variable $X$ (capsaicin content) and variable $Y$ (rating of spiciness intensity) controlled the influence of variable $\mathrm{Z}$ ( $\mathrm{pH}$, titratable acidity, salinity, free sugars, or free amino acids). The 
obtained first-order partial correlation coefficient $\left(\mathrm{r}_{\mathrm{xy} / \mathrm{z}}\right)$ is shown in Table 4. Pearson's correlation coefficient between spiciness intensity rating and capsaicinoid content was 0.777 at $p \leq 0.01$, whereas the first-order partial correlation coefficients $\left(\mathrm{r}_{\mathrm{xy} / \mathrm{z}}\right)$, calculated using Eq. 4 , were $0.814(\mathrm{pH}), 0.762$ (titratable acidity), 0.694 (salinity), 0.901 (free sugars), and 0.778 (free amino acids) (Table 4). Interestingly, the first-order partial correlation coefficient $\left(\mathrm{r}_{\mathrm{xy} / \mathrm{z}}\right)$ showed the greatest differential of 0.901 at $p \leq 0.01$. The first-order partial correlation coefficient differed from Pearson's correlation coefficient because the calculated numerical difference between " $\mathrm{r}_{\mathrm{xy} / \mathrm{z}}$ " [first-order partial correlation coefficient of capsaicin content $(\mathrm{X})$ and rating of spiciness intensity $(\mathrm{Y})$ without the influence of free sugar content $(\mathrm{Z})$ ] and " $\mathrm{r}_{\mathrm{xy} / \mathrm{z}}$ " [Pearson's correlation coefficient for capsaicin content $(X)$ and rating of spiciness intensity $(\mathrm{Y})$ ] was influenced by the free sugar content as the conditioned variable $\mathrm{Z}$. If the partial correlation coefficient differs significantly from the simple-correlation coefficient, the controlled variable $(\mathrm{Z})$ is strongly related to the other two variables. Regarding the influence of sugar components as neutralizers of the spiciness of chili peppers, Stevens and Lawless [37] demonstrated that sugars are highly effective for decreasing spiciness intensity in the mouth. Schneider et al. [33] reported that the low rating for the sensory spiciness of commercial salsas may be due to sugars. Furthermore, it is well known that the effects of palate cleansers are markedly increased by addition of sucrose. These results were supported by various studies showing the effects of sucrose [38,39]. According to Steiner et al. [36], sweet taste is known to cause pleasant emotions in people of all ages, and sucrose allows people and animals to endure pain better when they taste spiciness $[39,40]$. This notion supports our finding that the free sugar content exerted the greatest effect on the relationship between spiciness intensity rating and capsaicin content of commercial kimchi.

Table 4. Partial correlation coefficients showing the relationships among physicochemical properties, capsaicin contents, and rating of spiciness intensity.

\begin{tabular}{|c|c|c|c|c|c|c|c|c|c|c|c|c|}
\hline & \multicolumn{2}{|c|}{$\begin{array}{l}\text { Pearson's } \\
\text { Correlation }\end{array}$} & \multicolumn{10}{|c|}{ Partial Correlation } \\
\hline & \multirow[b]{2}{*}{ Cap $^{1}$} & \multirow[b]{2}{*}{$\mathrm{PIR}^{2}$} & \multicolumn{2}{|c|}{$\mathrm{pH}^{3}$} & \multicolumn{2}{|c|}{$\begin{array}{c}\text { Titratable Acidity } \\
{ }^{3}(\%)\end{array}$} & \multicolumn{2}{|c|}{ Salinity ${ }^{3}(\%)$} & \multicolumn{2}{|c|}{$\begin{array}{l}\text { Free Sugars } \\
(\mathrm{mg} / \mathrm{mL})\end{array}$} & \multicolumn{2}{|c|}{$\begin{array}{c}\text { Free Amino } \\
\text { Acids }(\mathrm{mg} / \mathrm{kg})\end{array}$} \\
\hline & & & CAP & PIR & CAP & PIR & Cap & PIR & Cap & PIR & Cap & PIR \\
\hline Cap & 1.000 & 0.777 & 0 & $\begin{array}{c}0.814 \\
* * * \\
0.001\end{array}$ & 0 & $\begin{array}{c}0.762 * * \\
0.003\end{array}$ & 0 & $\begin{array}{c}0.694 * \\
0.021\end{array}$ & 0 & $\begin{array}{c}0.901 \\
* * * \\
0.009\end{array}$ & 0 & $\begin{array}{c}0.778 \\
* * * \\
0.008\end{array}$ \\
\hline PIR & 0.777 & 1.000 & $\begin{array}{c}0.814 \\
* * * \\
0.001\end{array}$ & 0 & $\begin{array}{c}0.762^{* *} \\
0.003\end{array}$ & 0 & $\begin{array}{c}0.694 * \\
0.021\end{array}$ & 0 & $\begin{array}{c}0.901 \\
* * * \\
0.009\end{array}$ & 0 & $\begin{array}{c}0.778 \\
* * * \\
0.008\end{array}$ & 0 \\
\hline
\end{tabular}

\footnotetext{
${ }^{1}$ Capsaicinoid content (variable $\left.\mathrm{X}\right) ;{ }^{2}$ spiciness intensity rating (variable $\mathrm{Y}$ ) ${ }^{3}$ condition variable $\mathrm{Z} .{ }^{*} p \leq 0.05,{ }^{* *} p \leq 0.01,{ }^{* * *} p \leq 0.001$.
}

\section{Conclusions}

Using partial correlation coefficients, we demonstrated that the sensory spiciness caused by capsaicinoids is influenced by the physicochemical properties of kimchi such as $\mathrm{pH}$, titratable acidity, salinity, free sugars, and free amino acids. Among the investigated physicochemical properties of kimchi, free sugar content exerted the greatest direct and indirect effects on the rating of spiciness intensity. Our findings suggest that the capsaicinoid content cannot be used exclusively to rate the spiciness of commercial kimchi.

Supplementary Materials: The following are available online at https:/ / www.mdpi.com/2304-815 8/10/1/86/s1, Table S1: Free sugar contents (mg/mL) of 13 commercial kimchi samples, Table S2: Free amino acid contents $(\mathrm{mg} / \mathrm{kg})$ of 13 commercial kimchi samples.

Author Contributions: Conceptualization, S.-R.Y. and Y.-M.D.; methodology, S.-R.Y.; software, S.-Y.K.; validation, S.-R.Y., Y.-M.D., and S.-Y.K.; formal analysis, S.-Y.Y.; data curation, S.-R.Y.; writingoriginal draft preparation, S.-R.Y.; writing—review and editing, J.-H.H. and M.K.K.; visualization, 
S.-R.Y; supervision, J.-H.H.; project administration, J.-H.H.; and funding acquisition, J.-H.H. All authors have read and agreed to the published version of the manuscript.

Funding: This research was supported by the World Institute of Kimchi (grant numbers KE1903-3 and KE2002-2) and funded by the Ministry of Science and ICT, the Republic of Korea.

Institutional Review Board Statement: Not applicable.

Informed Consent Statement: Not applicable.

Data Availability Statement: The data presented in this study are available on request from the corresponding author.

Acknowledgments: This work was partially supported by the Ministry of Science and ICT (Republic of Korea) under the project WIKIM (KE1903-3 and KE2002-2).

Conflicts of Interest: The authors declare no conflict of interest.

\section{References}

1. Ji, Y.S.; Kim, H.N.; Park, H.J.; Lee, J.E.; Lee, H.J.; Shin, H.K.; Kim, B.J.; Franz, C.M.A.P.; Holzapfel, W.H. Functionality and safety of lactic bacterial strains from Korean kimchi. Food Control 2013, 31, 467-473. [CrossRef]

2. Kim, M.K.; Lee, M.A.; Lee, K.G. Determination of compositional quality and volatile flavor characteristics of radish-based Kimchi suitable for Chinese consumers and its correlation to consumer acceptability. Food Sci. Biotechnol. 2018, 27, 1265-1273. [CrossRef]

3. Kang, S.; Kim, S.J.; Kim, S.H.; Lee, J.H.; Park, S.Y.; Ha, S.D. Comparison of the murine norovirus-1 inactivation in cabbage Kimchi with two different salinities during storage. Food Res. Int. 2016, 84, 96-101. [CrossRef]

4. Cliff, M.; Heymann, H. Descriptive analysis of oral pungency. J. Sens. Stud. 1992, 7, 279-290. [CrossRef]

5. Guzmán, I.; Bosland, P.W. Sensory properties of chili pepper heat-And its importance to food quality and cultural preference. Appetite 2017, 117, 186-190. [CrossRef] [PubMed]

6. Lee, M.A.; Choi, Y.J.; Kim, M.K. Qualitative consumer preference studies on Korean-style kimchi in Chinese living in Korea. J. East Asian Soc. Diet. Life 2017, 27, 185-193. [CrossRef]

7. Jang, S.H.; Kim, M.J.; Lim, J.Y.; Hong, J.H. Cross-cultural comparison of consumer acceptability of Kimchi with different degree of fermentation. J. Sens. Stud. 2016, 31, 124-134. [CrossRef]

8. Park, H.J.; Ko, J.M.; Lim, J.Y.; Hong, J.H. American consumers' perception and acceptance of an ethnic food with strong flavor: A case study of Kimchi with varying levels of red pepper and fish sauce. J. Sci. Food Agric. 2020, 100, 2348-2357. [CrossRef] [PubMed]

9. Ku, K.H.; Lee, K.A.; Park, J.B. Physicochemical properties and sensory evaluation for the heat level (hot taste) of Korean red pepper powder. Prev. Nutr. Food Sci. 2012, 17, 29-35. [CrossRef]

10. Perucka, I.; Oleszek, W. Extraction and determination of capsaicinoids in fruit of hot pepper Capsicum annuum L. by spectrophotometry and high-performance liquid chromatography. Food Chem. 2000, 71, 287-291. [CrossRef]

11. Gibbs, H.A.A.; O'Garro, L.W. Capsaicin content of West Indies hot pepper cultivars using colorimetric and chromatographic techniques. HortScience 2004, 39, 132-135. [CrossRef]

12. Barbero, G.F.; Palma, M.; Barroso, C.G. Pressurized liquid extraction of capsaicinoids from peppers. J. Agric. Food Chem. 2006, 54, 3231-3236. [CrossRef] [PubMed]

13. Peña-Alvarez, A.; Ramírez-Maya, E.; Alvarado-Suárez, L.A. Analysis of capsaicin and dihydrocapsaicin in peppers and pepper sauces by solid phase microextraction-gas chromatography-mass spectrometry. J. Chromatogr. A 2009, 1216, 2843-2847. [CrossRef] [PubMed]

14. Kaale, E.; Van Schepdael, A.; Roets, E.; Hoogmartens, J. Determination of capsaicinoids in topical cream by liquid-Liquid extraction and liquid chromatography. J. Pharm. Biomed. Anal. 2002, 30, 1331-1337. [CrossRef]

15. Kozukue, N.; Han, J.S.; Kozukue, E.; Lee, S.J.; Kim, J.A.; Lee, K.R.; Levin, C.E.; Friedman, M. Analysis of eight capsaicinoids in peppers and pepper-containing foods by high-performance liquid chromatography and liquid chromatography-mass spectrometry. $J$. Agric. Food Chem. 2005, 53, 9172-9181. [CrossRef]

16. Liu, L.; Chen, X.; Liu, J.; Deng, X.; Duan, W.; Tan, S. Determination of capsaicin and dihydrocapsaicin in Capsicum anuum and related products by capillary electrophoresis with a mixed surfactant system. Food Chem. 2010, 119, 1228-1232. [CrossRef]

17. Chai, J.Y.; Kim, M.S.; Han, I.K.; Lee, S.Y.; Yeo, I.H. Relationships between the content and sensory evaluation of pungent principles in red pepper. Anal. Sci. Technol. 1994, 7, 541-545.

18. Lee, H.D.; Kim, M.H.; Lee, C.H. Relationship between the taste components and sensory preference of Korean red peppers. Korean J. Food Sci. Technol. 1992, 24, 266-271.

19. Chambers, E.; Lee, J.H.; Chun, S.; Miller, A.E. Development of a exicon for commercially available cabbage (Baechu) Kimchi. J. Sens. Stud. 2012, 27, 511-518. [CrossRef]

20. Lee, K.W.; Kim, K.O. Effects of fat and sucrose in palate cleansers on discrimination of burning sensation of capsaicin samples. Food Sci. Biotechnol. 2013, 22, 691-696. [CrossRef] 
21. AOAC (Official Methods of Analysis of the Association of Official Analytica 1 Chemists). Sodium chloride in canned vegetable, Method 971.27. In Official Methods of Analysis of the Association of Official Analytical Chemists International, 17th ed.; Horwitz, W., Ed.; Byrd Press Inc.: Richmond, VA, USA, 2000; Volume II, pp. 7-8.

22. Park, B.Y.; Yang, J.S.; Moon, E.W.; Seo, H.Y.; Ha, J.H. Influence of capsaicinoids content on the microbial community during kimchi fermentation. J. Microbiol. Biotechnol. 2019, 29, 1580-1590. [CrossRef] [PubMed]

23. Hootman, R. (Ed.) Manual on Descriptive Analysis Testing for Sensory Evaluation; ASTM International: West Conshohocken, PA, USA, 1992. [CrossRef]

24. Lee, J.H.; Jeong, D.W.; Kim, M.K. Influence of bacterial starter cultures on the sensory characteristics of doenjang, a fermented soybean paste, and their impact on consumer hedonic perception. J. Sens. Stud. 2019, 34, e12508. [CrossRef]

25. Sokal, R.; Rohlf, F.J. Biometry: The Principles and Practice of Statistics in Biological Research, 3rd ed.; W. H. Freeman and Company: New York, NY, USA, 1995; pp. 21-25.

26. Lim, J.H.; Park, S.S.; Jeong, J.W.; Park, K.J.; Seo, K.H.; Sung, J.M. Quality characteristics of kimchi fermented with abalone or sea tangle extracts. J. Korean Soc. Food Sci. Nutr. 2013, 42, 450-456. [CrossRef]

27. Lee, M.; Song, J.H.; Jung, M.Y.; Lee, S.H.; Chang, J.Y. Large-scale targeted metagenomics analysis of bacterial ecological changes in 88 kimchi samples during fermentation. Food Microbiol. 2017, 66, 173-183. [CrossRef] [PubMed]

28. Park, S.E.; Yoo, S.A.; Seo, S.H.; Lee, K.I.; Na, C.S.; Son, H.S. GC-MS based metabolomics approach of Kimchi for the understanding of Lactobacillus plantarum fermentation characteristics. LWT Food Sci. Technol. 2016, 68, 313-321. [CrossRef]

29. Hong, S.I.; Park, J.S.; Park, N.H. Relationships between fermentative gas pressure and quality changes of packaged kimchi at different temperatures. Korean J. Food Sci. Technol. 1994, 26, 770-775.

30. Hong, S.I.; Park, J.S.; Park, N.H. Quality changes of commercial kimchi products by different packaging methods. Korean J. Food Sci. Technol. 1995, 27, 112-118.

31. Jung, J.Y.; Lee, S.H.; Kim, J.M.; Park, M.S.; Bae, J.W.; Hahn, Y.; Madsen, E.L.; Jeon, C.O. Metagenomic analysis of kimchi, a traditional Korean fermented food. Appl. Environ. Microbiol. 2011, 77, 2264-2274. [CrossRef]

32. Zhao, C.J.; Schieber, A.; Gänzle, M.G. Formation of taste-active amino acids, amino acid derivatives and peptides in food fermentations-A review. Food Res. Int. 2016, 89, 39-47. [CrossRef]

33. Todd, P.H.; Bensinger, M.G.; Biftu, T. Determination of pungency due to capsicum by gas-liquid chromatography. J. Food Sci. 1977, 42, 660-665. [CrossRef]

34. Schneider, D.J.; SeuB-Baum, I.; Schlich, E. Comparison between chemical senses thresholds for capsaicin and dihydrocapsaicin in aqueous solutions and identification of the area of burning sensation. Adv. J. Food Sci. Technol. 2014, 6, 36-41. [CrossRef]

35. Salkind, N.J. Statistics for People Who (Think They) Hate Statistics, 5th ed.; SAGE Publications: Newbury Park, CA, USA, 2016; Volume 127-128.

36. Melissa, A.S.; Raghuraj, K.R.; Lakshminarayanan, S. Partial correlation metric based classifier for food product characterization. J. Food Eng. 2009, 90, 146-152. [CrossRef]

37. Stevens, D.A.; Lawless, H.T. Putting out the fire: Effects of tastants on oral chemical irritation. Percept. Psychophys. 1986, 39, 346-350. [CrossRef]

38. Steiner, J.E.; Glaser, D.; Hawilo, M.E.; Berridge, K.C. Comparative expression of hedonic impact: Affective reactions to taste by human infants and other primates. Neurosci. Biobehav. Rev. 2001, 25, 53-74. [CrossRef]

39. Blass, E.M.; Shah, A. Pain-reducing properties of sucrose in human newborns. Chem. Sens. 1995, 20, 29-35. [CrossRef] [PubMed]

40. Lewkowski, M.D.; Ditto, B.; Roussos, M.; Young, S.N. Sweet taste and blood pressure-related analgesia. Pain 2003, 106, 181-186. [CrossRef] 